\title{
Enhancement of Electrochemical Stability about Silicon/Carbon Composite Anode Materials for Lithium Ion Batteries
}

\author{
Wei Xiao, Chang Miao, Xuemin Yan, Qing Sun, and Ping Mei \\ College of Chemistry and Environmental Engineering, Yangtze University, Jingzhou 434023, China \\ Correspondence should be addressed to Wei Xiao; xwylyq2009@gmail.com
}

Received 2 December 2014; Revised 19 January 2015; Accepted 19 January 2015

Academic Editor: Jiayu Wan

Copyright (C) 2015 Wei Xiao et al. This is an open access article distributed under the Creative Commons Attribution License, which permits unrestricted use, distribution, and reproduction in any medium, provided the original work is properly cited.

\begin{abstract}
Silicon/carbon (Si/C) composite anode materials are successfully synthesized by mechanical ball milling followed by pyrolysis method. The structure and morphology of the composite are characterized by X-ray diffraction and scanning electron microscopy and transmission electron microscope, respectively. The results show that the composite is composed of Si, flake graphite, and phenolic resin-pyrolyzed carbon, and Si and flake graphite are enwrapped by phenolic resin-pyrolyzed carbon, which can provide not only a good buffering matrix but also a conductive network. The Si/C composite also shows good electrochemical stability, in which the composite anode material exhibits a high initial charge capacity of $805.3 \mathrm{mAh} \mathrm{g}^{-1}$ at $100 \mathrm{~mA} \mathrm{~g}^{-1}$ and it can still deliver a high charge capacity of $791.7 \mathrm{mAh} \mathrm{g}^{-1}$ when the current density increases to $500 \mathrm{~mA} \mathrm{~g}^{-1}$. The results indicate that it could be used as a promising anode material for lithium ion batteries.
\end{abstract}

\section{Introduction}

Rechargeable lithium ion batteries are key components of portable electronic devices and electrical vehicles due to their high energy density, long cycle life, and high power [1-3]. In this area, the anode materials play an important role in lithium ion batteries. Though graphite is now widely used as the commercial anode material, the low theoretical capacity about $372 \mathrm{mAh} \mathrm{g}^{-1}$ is still an obstacle for the lithium ion batteries to further develop $[4,5]$. In this regard, $\mathrm{Si}$ has attracted much attention as anode material for its high theoretical capacity about $4200 \mathrm{mAhg}^{-1}[6,7]$. However, some shortcomings, such as the poor capacity retention resulting from the low intrinsic electronic conductivity, the over three times volume change during the $\mathrm{Li}$ insertion and extraction processes and the unstable solid electrolyte interface (SEI), are still the thresholds that prevent the materials from practical application [8-11]. Therefore, various forms of Si-based materials have been explored to overcome these disadvantages, such as limiting the volume change by coating various materials $[12,13]$, buffering the volume expansion by constructing new frame work for Si grains $[14,15]$, and synthesizing nanodispersed $\mathrm{Si}$ particles to create enough interspace in anode materials by chemical vapor deposition
(CVD) and thermal vapor deposition (TVD) [16, 17]. And carbon coating has been considered as the most effective and feasible method to improve the performance of Si-based materials, which promotes extensive efforts in the development of synthesis methods, such as ball milling, mechanical milling, combination of pyrolysis with mechanical milling, sol-gel, pyrolysis, and CVD/TVD [18, 19]. Among these techniques, the mechanical milling combining with pyrolysis is a flexible and scalable process to prepare $\mathrm{Si} / \mathrm{C}$ composite material at present. Therefore, the Si/graphite composite materials coated with carbon are prepared via mechanical milling followed by pyrolysis in this work. The obtained $\mathrm{Si} / \mathrm{C}$ composite used as anode material for lithium ion batteries is studied in respect of structural, morphological, and electrochemical properties. The effect of carbon coating and mechanical milling on the electrochemical performance is also investigated in the paper.

\section{Experimental}

2.1. Preparation of Si/C Composite. Silicon/carbon (Si/C) composite was synthesized by mechanical milling followed by pyrolysis. The synthetic procedures can be briefly described as follows: (1) mixing raw materials of $1.00 \mathrm{~g}$ nano-Si (>99.9\%, 
30 nm, Shuitian Materials Technology Co., Ltd., Shanghai, China), $4.00 \mathrm{~g}$ graphite (>99\%, $\sim 0.5 \mu \mathrm{m}$, Qingdao Tianhe Graphite Co., Ltd., Shandong, China), and $3.85 \mathrm{~g}$ phenolic resin by magnetic stirring and ultrasonic treatment, using alcohol as dispersing agent; (2) ball milling for $10 \mathrm{~h}$ and drying in the oven at $90^{\circ} \mathrm{C}$ overnight (denoted as the precursor); (3) pyrolysis at $750^{\circ} \mathrm{C}$ for $2 \mathrm{~h}$ under argon atmosphere.

2.2. Properties Characterization. The powder X-ray diffraction (XRD, Rint-2000, Rigaku, Japan) using $\mathrm{Cu} \mathrm{K} \alpha$ radiation was employed to identify the crystalline phase of the synthesized materials. Thermal analysis of the as-prepared samples was performed on a SDT Q600 TG-DTA (TE, USA) apparatus between room temperature and $1000^{\circ} \mathrm{C}$ at a heating

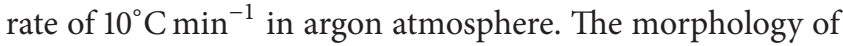
the samples was observed by scanning electron microscope (SEM, JEOL, JSM-5612LV) with an accelerating voltage of $20 \mathrm{kV}$, and the microstructure of the composite was investigated by transmission electron microscope (TEM, Tecnai G12, $200 \mathrm{kV})$.

The electrochemical performance was evaluated via a standard $\mathrm{Li} / / \mathrm{LiPF}_{6}(\mathrm{EC}: \mathrm{EMC}: \mathrm{DMC}=1: 1: 1 ; \mathrm{v} / \mathrm{v} / \mathrm{v}) / / \mathrm{Si} / \mathrm{C}$ CR2025 coin cell. To fabricate the working electrode, $80 \mathrm{wt} . \%$ active materials, $10 \mathrm{wt} . \%$ acetylene black, and $10 \mathrm{wt} . \%$ poly(vinylidene fluoride) were firstly blended in $N$-methyl pyrrolidinone to obtain homogeneous slurry, and then the slurry was spread uniformly on a copper foil and dried at $120^{\circ} \mathrm{C}$ for $12 \mathrm{~h}$ in the air; the desirable working electrode can be obtained after being cut into round pieces with an area of $1.54 \mathrm{~cm}^{2}$. The whole assembling processes of the cell were carried out in a dry argon-filled glove box. The chargedischarge tests of the cell were performed on a Neware battery tester (Neware, Shenzhen) with cut-off voltage of 0.01$2.00 \mathrm{~V}$ at room temperature. The electrochemical impedance measurement was performed on a CHI660A electrochemical workstation (Chenhua, Shanghai), in which the impedance spectra were recorded with $\mathrm{AC}$ amplitude of $5 \mathrm{mV}$ from $0.01 \mathrm{~Hz}$ to $100 \mathrm{kHz}$.

\section{Results and Discussion}

3.1. Thermal Analysis of the Precursor. The TG-DTA curves of the precursor are shown in Figure 1. It can be obviously observed that the TG curve presents three stages of weight loss at 25 260, 260 560, and 560 1000 $\mathrm{C}$, which represent the loss of absorbed water, the decomposition of phenolic resin to form excess phenolic resin-pyrolyzed carbon, and the further evaporation of phenolic resin, respectively. DTA curve displays two distinctly corresponding endothermic peaks, which correspond to the aforementioned first two stages. As for the third stage, the weight loss is not remarkable in Figure 1. It is worthy to note that the change of weight loss becomes insignificant when the pyrolysis temperature is above $750^{\circ} \mathrm{C}$. Therefore, in order to obtain desirable $\mathrm{Si} / \mathrm{C}$ composites, the blended precursor was pyrolyzed at $750^{\circ} \mathrm{C}$ in this work.

3.2. Structural Analysis of the Materials. The XRD patterns of the precursor and $\mathrm{Si} / \mathrm{C}$ composite material are shown in

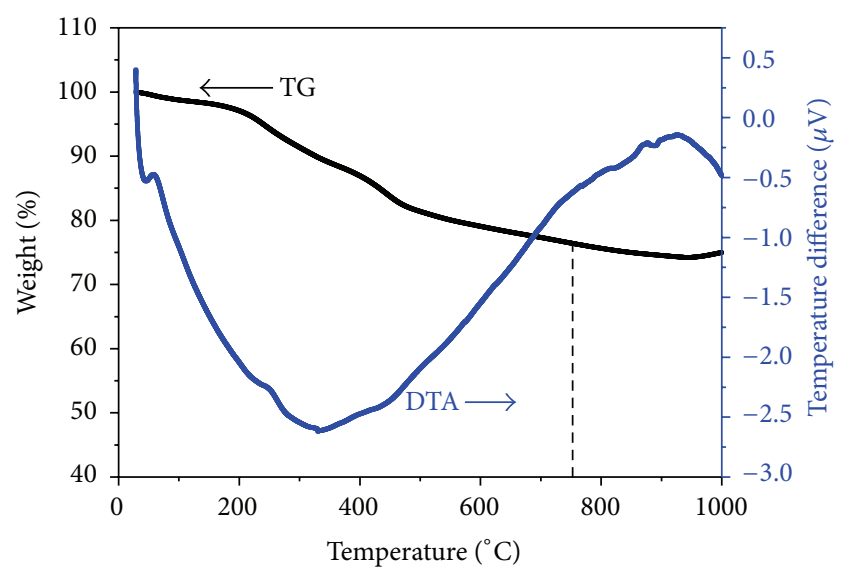

FIGURE 1: TG-DTA curves of the precursor.

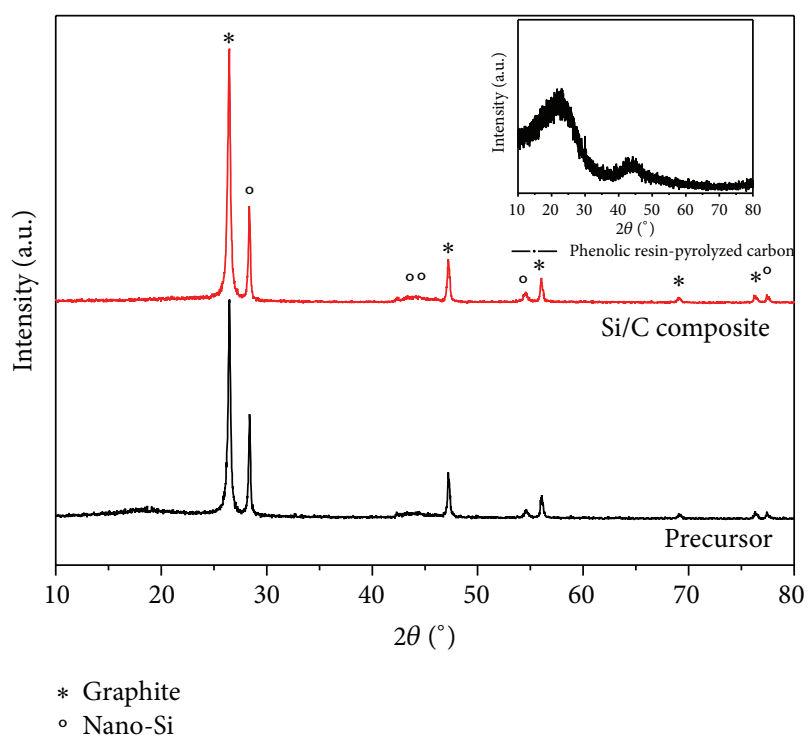

FIGURE 2: X-ray diffraction patterns of the precursor and the Si/C composite.

Figure 2. As demonstrated in Figure 2, both XRD patterns of the precursor and $\mathrm{Si} / \mathrm{C}$ composite show the diffraction peaks of flake graphite $\left(2 \theta=26.6,42.5,43.5,54.7\right.$, and $77.6^{\circ}$, PDF\#41-1487) and silicon $\left(2 \theta=28.4,47.3,56.1,69.1\right.$, and $76.4^{\circ}$, PDF\#27-1407), which corresponds to the (002), (100), (101), (004), and (110) plane of flake graphite and the (111), (220), (311), (400), and (331) plane of Si, respectively [20]. These results indicate that the pyrolysis process would not destroy the basic structure of the composite material. Furthermore, the broadened diffraction peak around $2 \theta=23^{\circ}$ comes from the amorphous phenolic resin-pyrolyzed carbon as shown on the upper right corner in Figure 2. The results suggest that no other impurity phase is detected in the composite and the composite is composed of flake graphite, nano-Si, and phenolic resin-pyrolyzed carbon, which can be explained that the desirable composite materials can be successfully prepared by the mechanical milling followed by pyrolysis method. 


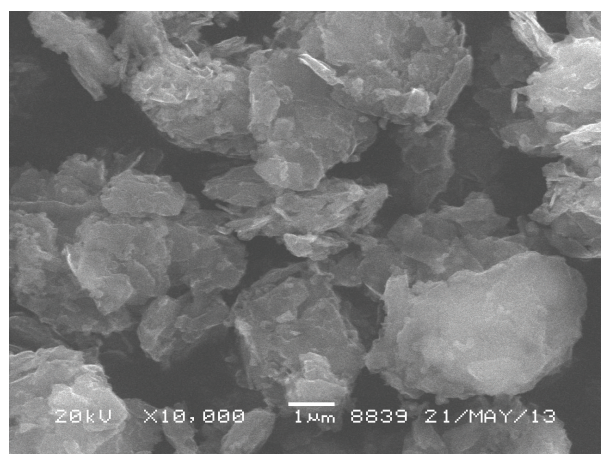

(a)

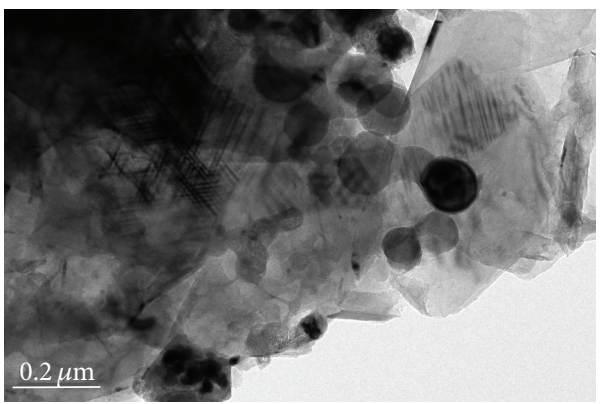

(c)

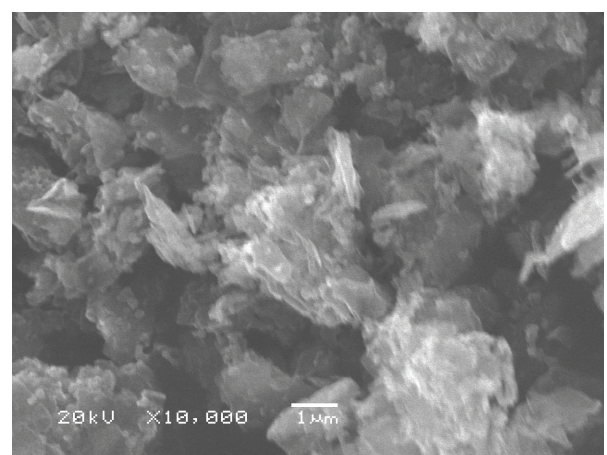

(b)

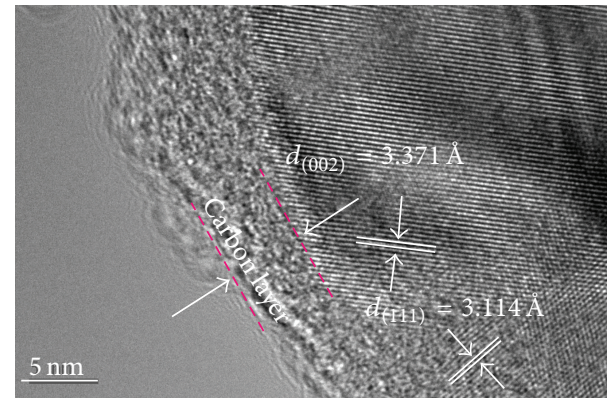

(d)

FIGURE 3: SEM images of the precursor (a) and the Si/C composite (b), TEM (c), and HRTEM (d) images of the Si/C composite.

3.3. Morphology of the Materials. The morphology of the precursor and the obtained $\mathrm{Si} / \mathrm{C}$ composite material were observed by SEM as shown in Figures 3(a) and 3(b). The morphology of $\mathrm{Si} / \mathrm{C}$ material inherits the morphology of the precursor; most of the particles exhibit scaly shape and are micron in dimension. It should be noted that $\mathrm{Si} / \mathrm{C}$ material is looser than the precursor, which can be mainly attributed to the decomposition of phenolic resin during pyrolysis [21, 22]. Figures 3(c) and 3(d) show the TEM and HRTEM images of the $\mathrm{Si} / \mathrm{C}$ composite, respectively. It can be obviously observed that the composite particles are composed of flake graphite, nano-Si, and phenolic resin-pyrolyzed carbon, which are in concordance with the results of XRD analysis. Furthermore, the phenolic resin-pyrolyzed carbon is coated on the surface of the composite sphere perfectly, which not only provides a good buffering matrix but also constructs the connection network of flake graphite and Si particles [23].

3.4. Electrochemical Performance. The cut-off voltages range of the cells was chosen as $0.01-2.00 \mathrm{~V}$, and the discharge current density is limited at $100 \mathrm{~mA} \mathrm{~g}^{-1}$. The voltage profiles of the $\mathrm{Si} / \mathrm{C}$ composite for the 1st, $2 \mathrm{nd}$, and 3 rd cycle are presented in Figure 4(a), respectively. It can be seen that the first charge capacity (reversible capacity corresponding to lithium extraction) of the composite is about $805.3 \mathrm{mAh} \mathrm{g}^{-1}$, and the initial columbic efficiency is $74.26 \%$, which is a little higher than the value of the previous report $[23,24]$. As known to us, the irreversible capacity of the first cycle is mainly attributed to the formation of a solid electrolyte interphase (SEI) film on the surface of electrode at $0.6 \sim 0.8 \mathrm{~V}$. It can be also seen from Figure $4(\mathrm{a})$ that there is a distinct potential platform below $0.2 \mathrm{~V}$ during the first insertion process, which can be assigned to the alloying process of the composite with lithium and the insertion of lithium ions into the carbon host. And the shift of the subsequent discharge curves presented in the following cycles may be ascribed to the typical phase transformation of silicon from crystal to amorphous $[23,25,26]$. Another significant plateau at $0.45 \mathrm{~V}$ can also be found in Figure 4(a), which is attributed to the extraction processes of $\mathrm{Li}^{+}$from silicon. The charge-discharge cycling and coulombic efficiency curves of the $\mathrm{Si} / \mathrm{C}$ composite with and without ball milling at $100 \mathrm{mAg}^{-1}$ are shown in Figure 4(b). The coulombic efficiency of the composite with ball milling can quickly achieve a steady value about $98 \%$ after only three cycles, which gains much improvement compared to the Si/C composite without ball milling. And the capacity of the composite can maintain above $500 \mathrm{mAh} \mathrm{g}^{-1}$ after 40 cycles. The results show that ball milling plays a vital role in the cycling performance of the composite, which may be ascribed to the more active points formation by the mechanical activation. In order to further study the electrochemical performance, rate performance is also conducted and the corresponding curves are demonstrated in Figure 4(c). It can be seen from Figure 4(c) that both the first charge capacity and initial coulombic efficiency decrease with increasing current density, in which the first charge capacity of the composite at 100,200 , and $500 \mathrm{~mA} \mathrm{~g}^{-1}$ is about 805.3, 797.4 , and $791.7 \mathrm{mAh} \mathrm{g}^{-1}$, respectively, and the corresponding initial coulombic efficiency is $74.26 \%, 74.20 \%$, and $74.10 \%$, respectively. The cyclic performance of the Si/C composite at different current densities is also shown in Figure 4(d), and the capacity retention ratio is $89.58 \%, 79.46 \%$, and 


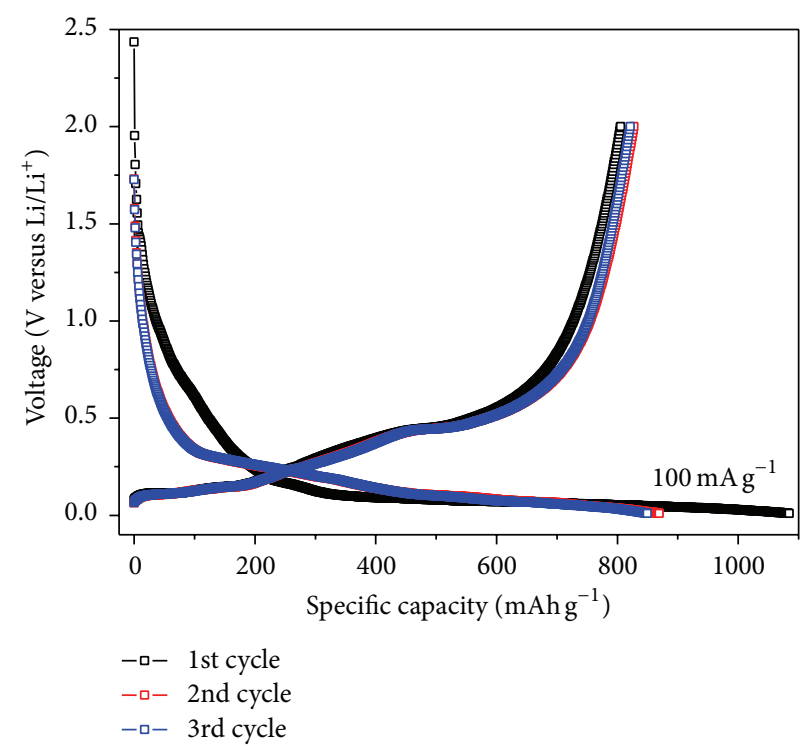

(a)

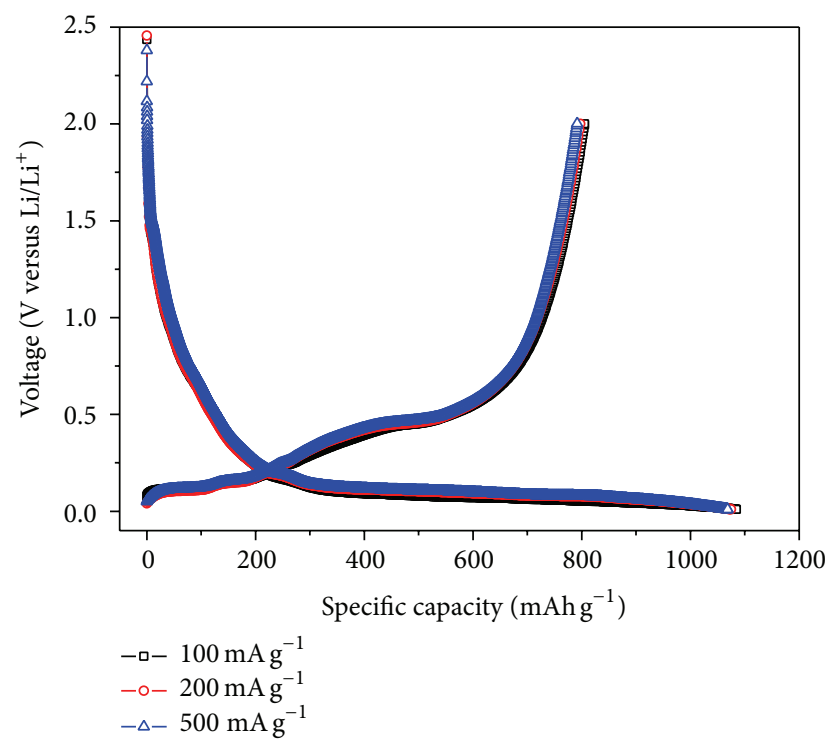

(c)

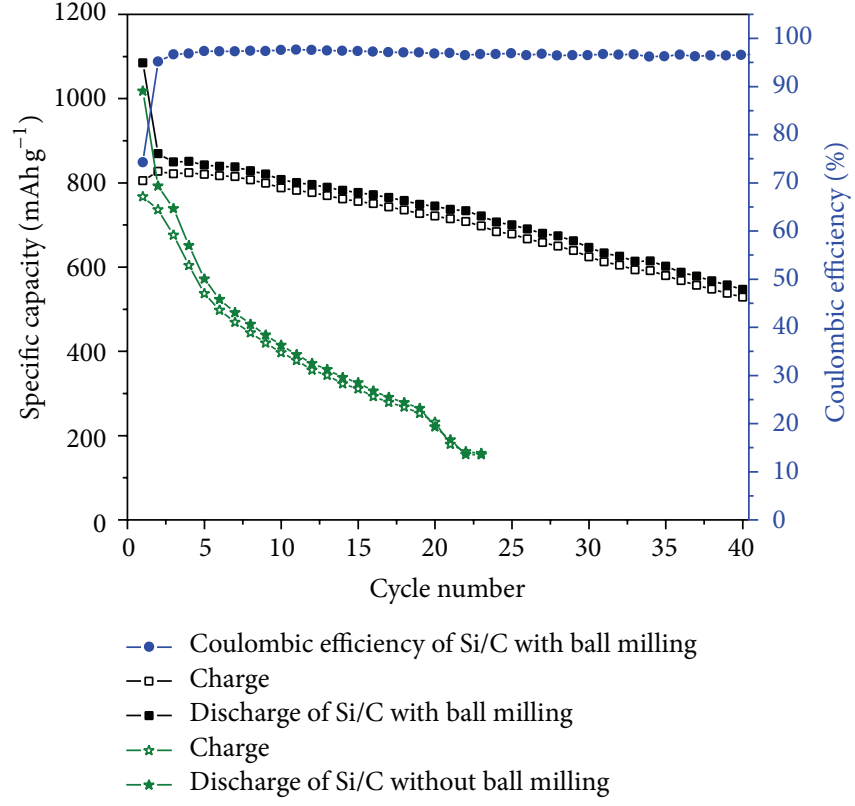

(b)

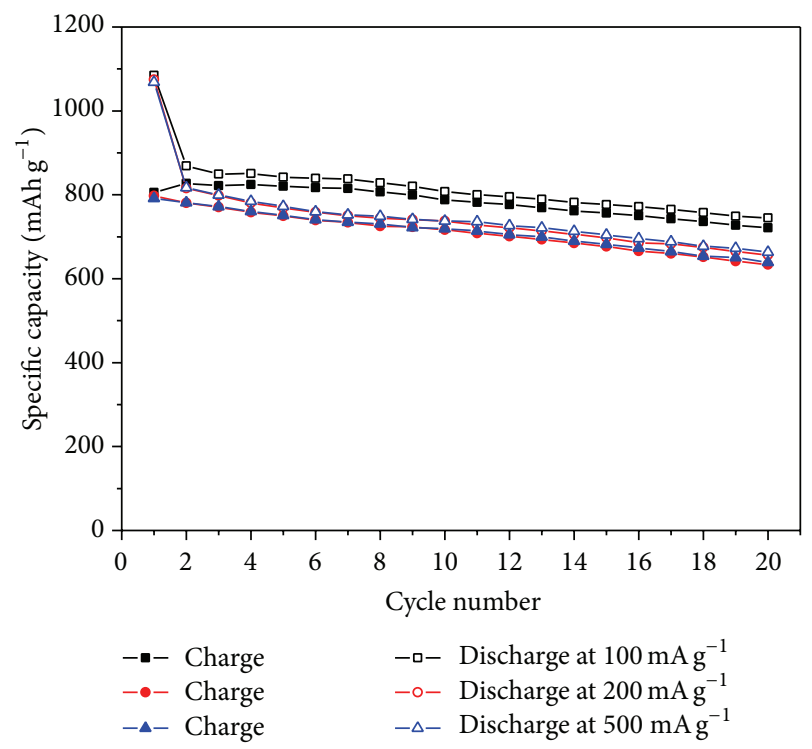

(d)

FIgURE 4: (a) The voltage profiles of $\mathrm{Si} / \mathrm{C}$ composites at $100 \mathrm{~mA} \mathrm{~g}^{-1}$; (b) the charge-discharge cycling curves of the $\mathrm{Si} / \mathrm{C}$ composite with and without ball milling at $100 \mathrm{~mA} \mathrm{~g}^{-1}$; (c) initial charge-discharge curves of the composites at different rates; (d) cycling curves of the composites at different rates.

$80.69 \%$ after 20 cycles, respectively. Therefore, there are reasons to believe that the $\mathrm{Si} / \mathrm{C}$ composite possesses better electrochemical performance, and this is associated with the effective attachment between $\mathrm{Si}$, graphite, and phenolic resin-pyrolyzed carbon, which can provide good electronic conductivity and avoid direct contact between Si particles and the electrolyte to improve the electrochemical stability of the assembled cell.

The electrochemical impedance spectra of the composite anodes after different cycles are shown in Figure 5(a). It can be obviously seen that all plots are composed of a compressed semicircle in high frequency and an inclined line in low frequency, which are attributed to the charge transfer process and lithium diffusion process, respectively. To investigate the charge-discharge behavior of the electrodes, the pattern in the impedance spectra can be fitted using the equivalent circuit described as $R_{s}$ in series with parallel $\left(\mathrm{CPE}_{1} R_{\mathrm{ct}}\right)$ and $W_{1}$ elements $\left\{R_{s}\left(\mathrm{CPE}_{1} R_{\mathrm{ct}}\right) W_{1}\right\}$ demonstrated in Figure $5(\mathrm{~b})$, in which $R_{s}$ is attributed to the ohmic resistance of the electrolyte and electrodes, $R_{\mathrm{ct}}$ represents the charge transfer resistance of electrochemical reactions, and $\mathrm{CPE}_{1}$ and $W_{1}$ are the capacitance of the interface and Warburg 


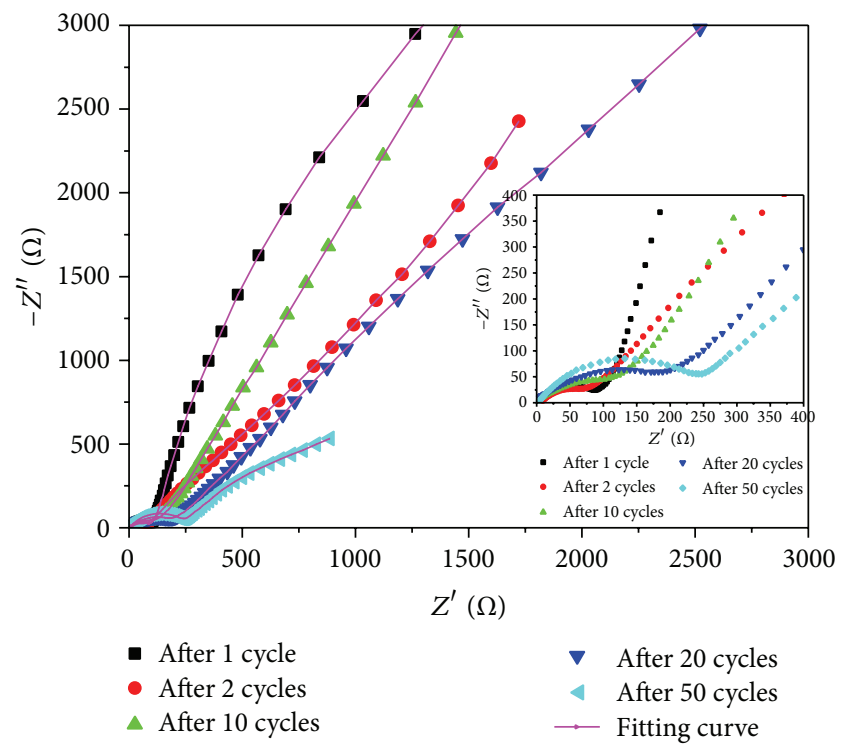

(a)

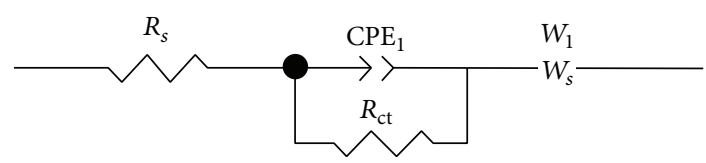

(b)

FIGURE 5: EIS curves of Si/C during different cycles (a) and the equivalent circuit for the impedance spectra (b).

diffusion-controlled resistance, respectively [27]. It is obviously observed that the EIS curves shown in Figure 5(a) can be well fitted by the equivalent circuit demonstrated in Figure 5(b). Furthermore, the resistance of $R_{s}, R_{\mathrm{ct}}$, and $W_{1}$ increases obviously in the 20 cycles, which is due to the destruction of the electrode. However, the resistance can remain stable value after 20 cycles, which can be attributed to the buffering of the $\mathrm{Si} / \mathrm{C}$ composite material to improve the electrochemical stability of the electrodes.

\section{Conclusions}

$\mathrm{Si} / \mathrm{C}$ composite anode material was successfully synthesized using the simple mechanical milling followed by pyrolysis method. The particles exhibit scaly shape and are micron in dimension; the phenolic resin-pyrolyzed carbon is coated on the surface of the composite sphere perfectly and constructs the connection network of flake graphite and nano-Si particles in the composite. Therefore, this composite shows good electrochemical performance, in which the composite exhibits not only high specific capacity with high coulombic efficiency in first cycle but also good cycle and rate performance. The primary results indicate that the as-prepared $\mathrm{Si} / \mathrm{C}$ composite material can be a promising anode material for high energy density and power demanding lithium-ion batteries.

\section{Conflict of Interests}

The authors declare that there is no conflict of interests regarding the publication of this paper.

\section{Acknowledgments}

This work has been carried out with the financial support of the National Natural Science Foundation of China under Contract no. 51404038 and Scientific Research and Development Funds of Basic Subject in Yangtze University under Contract no. 2013cjp20.

\section{References}

[1] P. G. Bruce, B. Scrosati, and J.-M. Tarascon, "Nanomaterials for rechargeable lithium batteries," Angewandte ChemieInternational Edition, vol. 47, no. 16, pp. 2930-2946, 2008.

[2] J. M. Tarascon and M. Armand, "Issues and challenges facing rechargeable lithium batteries," Nature, vol. 414, no. 6861, pp. 359-367, 2001.

[3] M. Armand and J. M. Tarascon, "Building better batteries," Nature, vol. 451, no. 7179, pp. 652-657, 2008.

[4] H. Fujimoto, "Development of efficient carbon anode material for a high-power and long-life lithium ion battery," Journal of Power Sources, vol. 195, no. 15, pp. 5019-5024, 2010.

[5] Y. P. Wu, E. Rahm, and R. Holze, "Carbon anode materials for lithium ion batteries," Journal of Power Sources, vol. 114, no. 2, pp. 228-236, 2003.

[6] J. R. Szczech and S. Jin, "Nanostructured silicon for high capacity lithium battery anodes," Energy \& Environmental Science, vol. 4, no. 1, pp. 56-72, 2011.

[7] J. Wang, Y. Chen, and L. Qi, "The development of silicon nanocomposite materials for Li-Ion secondary batteries," Open Materials Science Journal, vol. 5, pp. 228-235, 2011.

[8] Y. Fan, Q. Zhang, C. Lu, Q. Xiao, X. Wang, and B. K. Tay, "High performance carbon nanotube-Si core-shell wires with a rationally structured core for lithium ion battery anodes," Nanoscale, vol. 5, no. 4, pp. 1503-1506, 2013.

[9] J. Xiao, W. Xu, D. Wang et al., "Stabilization of silicon anode for Li-Ion batteries," Journal of the Electrochemical Society, vol. 157, no. 10, pp. A1047-A1051, 2010.

[10] M. N. Obrovac and L. Christensen, "Structural changes in silicon anodes during lithium insertion/extraction," Electrochemical and Solid-State Letters, vol. 7, no. 5, pp. A93-A96, 2004.

[11] J. W. Wang, Y. He, F. Fan et al., "Two-phase electrochemical lithiation in amorphous silicon," Nano Letters, vol. 13, no. 2, pp. 709-715, 2013.

[12] Y. Hwa, W.-S. Kim, S.-H. Hong, and H.-J. Sohn, "High capacity and rate capability of core-shell structured nano-Si/C anode for Li-ion batteries," Electrochimica Acta, vol. 71, pp. 201-205, 2012.

[13] K. Shin, D.-J. Park, H.-S. Lim, Y.-K. Sun, and K.-D. Suh, "Synthesis of silicon/carbon, multi-core/shell microspheres using solution polymerization for a high performance Li ion battery," Electrochimica Acta, vol. 58, no. 1, pp. 578-582, 2011.

[14] J. Nanda, M. K. Datta, J. T. Remillard, A. O'Neill, and P. N. Kumta, "In situ Raman microscopy during discharge of a high capacity silicon-carbon composite Li-ion battery negative electrode," Electrochemistry Communications, vol. 11, no. 1, pp. 235-237, 2009. 
[15] J. K. Lee, K. B. Smith, C. M. Hayner, and H. H. Kung, "Silicon nanoparticles-graphene paper composites for Li ion battery anodes," Chemical Communications, vol. 46, no. 12, pp. 20252027, 2010.

[16] L.-F. Cui, Y. Yang, C.-M. Hsu, and Y. Cui, "Carbon-silicon core-shell nanowires as high capacity electrode for lithium lon batteries," Nano Letters, vol. 9, no. 9, pp. 3370-3374, 2009.

[17] T. Umeno, K. Fukuda, H. Wang, N. Dimov, T. Iwao, and M. Yoshio, "Novel anode material for lithium-ion batteries: carboncoated silicon prepared by thermal vapor decomposition," Chemistry Letters, vol. 30, no. 11, pp. 1186-1187, 2001.

[18] U. Kasavajjula, C. Wang, and A. J. Appleby, "Nano- and bulksilicon-based insertion anodes for lithium-ion secondary cells," Journal of Power Sources, vol. 163, no. 2, pp. 1003-1039, 2007.

[19] M. K. Datta and P. N. Kumta, "Silicon, graphite and resin based hard carbon nanocomposite anodes for lithium ion batteries," Journal of Power Sources, vol. 165, no. 1, pp. 368-378, 2007.

[20] M. Su, Z. Wang, H. Guo et al., "Enhancement of the cyclability of a Si/Graphite@Graphene composite as anode for Lithiumion batteries," Electrochimica Acta, vol. 116, pp. 230-236, 2014.

[21] J. Bae, "Fabrication of carbon microcapsules containing silicon nanoparticles for anode in lithium ion battery," Colloid and Polymer Science, vol. 289, no. 11, pp. 1233-1241, 2011.

[22] P. Gao, J. Fu, J. Yang et al., "Microporous carbon coated silicon core/shell nanocomposite via in situ polymerization for advanced Li-ion battery anode material," Physical Chemistry Chemical Physics, vol. 11, no. 47, pp. 11101-11105, 2009.

[23] J. Lai, H. Guo, Z. Wang et al., "Preparation and characterization of flake graphite/silicon/carbon spherical composite as anode materials for lithium-ion batteries," Journal of Alloys and Compounds, vol. 530, pp. 30-35, 2012.

[24] M. Su, Z. Wang, H. Guo et al., "Enhanced cycling performance of $\mathrm{Si} / \mathrm{C}$ composite prepared by spray-drying as anode for Li-ion batteries," Powder Technology, vol. 249, pp. 105-109, 2013.

[25] P. Limthongkul, Y.-I. Jang, N. J. Dudney, and Y.-M. Chiang, "Electrochemically-driven solid-state amorphization in lithium-silicon alloys and implications for lithium storage," Acta Materialia, vol. 51, no. 4, pp. 1103-1113, 2003.

[26] Y. Liu, K. Hanai, J. Yang, N. Imanishi, A. Hirano, and Y. Takeda, "Morphology-stable silicon-based composite for Liintercalation," Solid State Ionics, vol. 168, no. 1-2, pp. 61-68, 2004.

[27] W. Xiao, X. Li, H. Guo, Z. Wang, Y. Zhang, and X. Zhang, "Preparation of core-shell structural single ionic conductor $\mathrm{SiO}_{2} @ \mathrm{Li}+$ and its application in PVDF-HFP-based composite polymer electrolyte," Electrochimica Acta, vol. 85, pp. 612-621, 2012. 

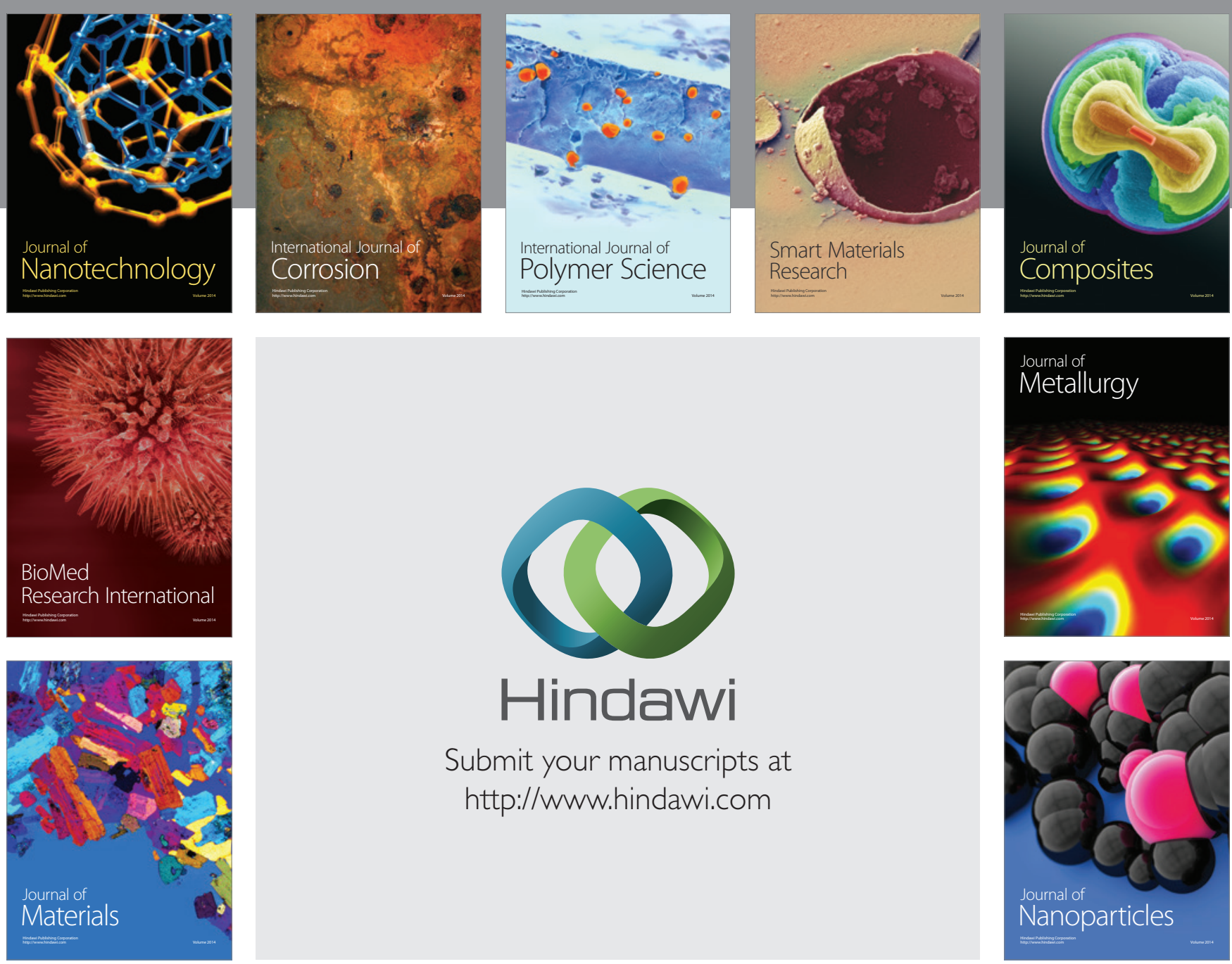

Submit your manuscripts at http://www.hindawi.com
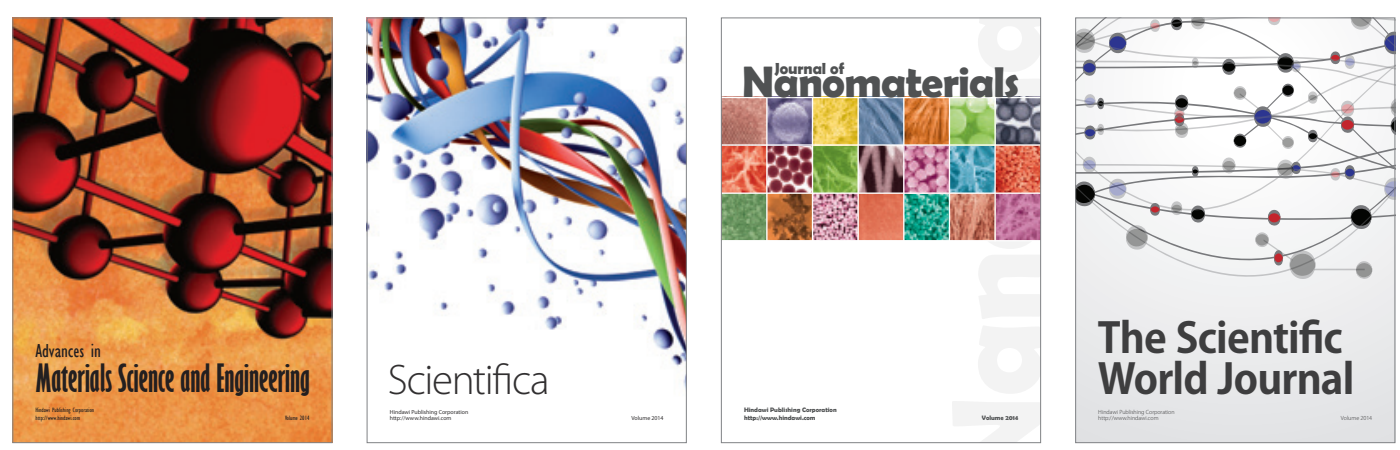

\section{The Scientific World Journal}
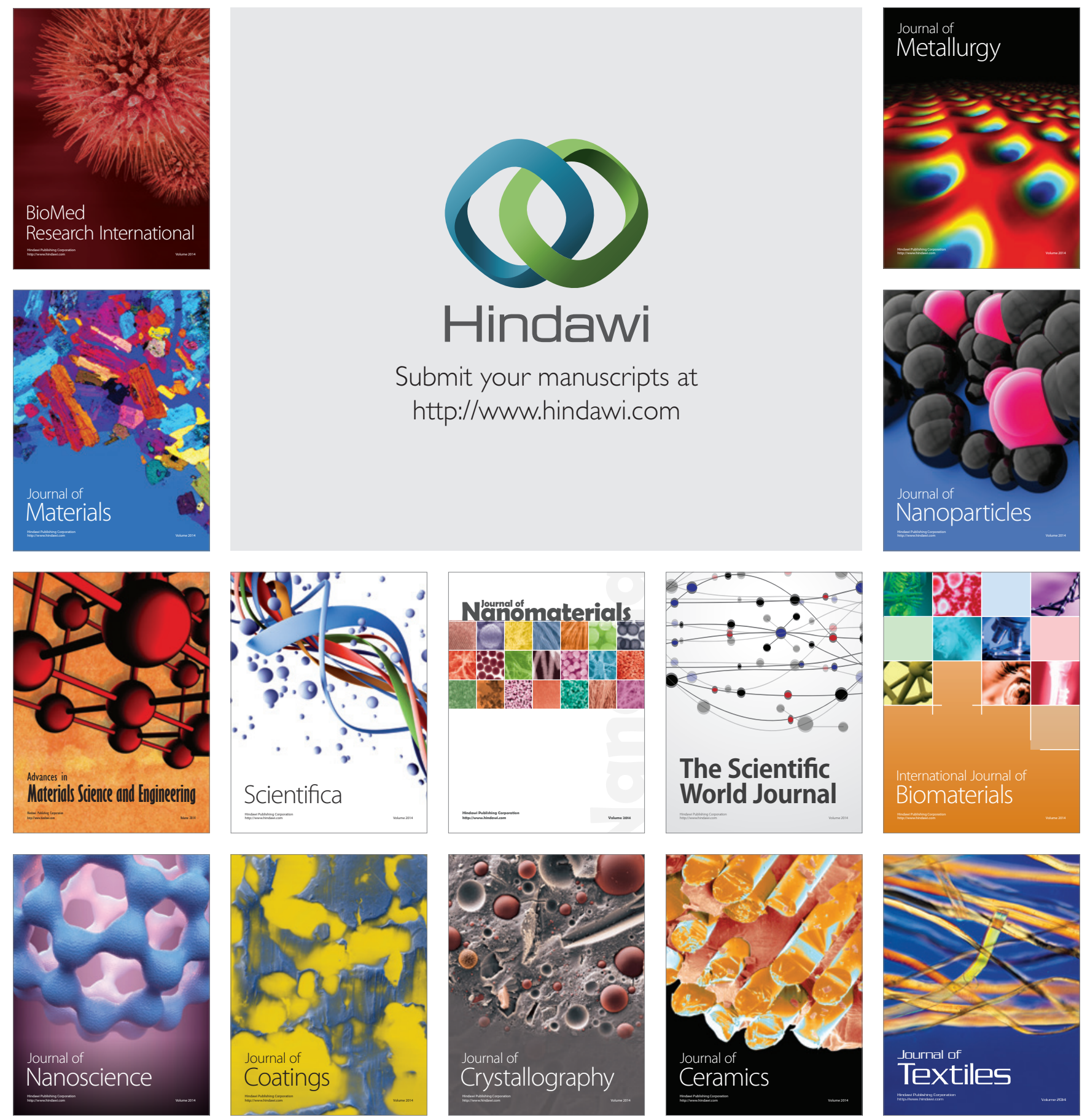